\title{
B R

Boletim Técnico do Instituto Agronômico do Estado de São Paulo

\begin{tabular}{lll}
\hline \hline Vol. $14 \quad$ Campinas, janeiro de 1955 & N. 6 \\
\hline \hline
\end{tabular}

\section{MELHORAMENTO DO CAFEEIRO}

\section{$\mathrm{X}$ - SELEÇÅO VISANDO ELIMINAR O DEFEITO "LOIAS VAZIAS DO FRUTO" NO CAFÉ MUNDO NOVO (*)}

\author{
A. Carvalho e H. Antunes Filho, engenheiros agrônomos, Seção de Genética do \\ Instituto Agronômico
}

\section{RESUMO}

As progênies de café Mundo Novo em estudo na Seção de Genética, desde 1943, se têm revelado altamente produtivas e vigorosas, porém apresentam numerosas plantas com rendimento desfavorável devido à alta incidência de lojas do fruto desprovidas de sementes.

Estudos detalhados sôbre a constituição dessas progênies, com relação a êsse defeito, foram iniciados em 1950 verificando-se, nessa ocasião, que algumas eram constituídas apenas de plantas normais, enquanto outras se apresentavam formadas de cafeeiros normais e plantas com o defeito de alta quantidade de lojas sem sementes.

A selcção foi dirigida a fim de eliminar, da população Mundo Novo, êsse grave defeito. Resolveu-se multiplicar apenas os cafeeiros mais produtivos das melhores progênies e que não apresentassem o defeito de alta quantidade de lojas vazias, pois seria de esperar que suas progênies fossem constituídas de plantas normais, a julgar pelos dados então obtidos nos descendentes do cafeeiro bourbon $n .^{\circ} 44$, que também apresentava o mesmo defeito.

Os resultados da amostragem realizada na primeira plantação de café Mundo Novo formada com essas sementes selecionadas, e discutidos no presente trabalho, dão indicações de que a seleçāo foi bastante eficiente, reduzindo a incidência de plantas com o defeito, de $50 \%$ na população original para cêrca de 2 a $7 \%$ nesta nova plantação. Em vista dêstes resultados as sementes aí colhidas em 1953 foram aproveitadas para sdstribuição aos lavradores de São Paulo, pela Divisão de Fomento Agrícola, a fim de ie formarem 148 piantações modêlo dessa nova variedade comercial.

- As comparações feitas, entre as produções de café beneficiado, calculadas a partir do rendimento para os cafeeiros de mais alta produçāo de cereja, indicam que se deve primeiramente concentrar a seleção em plantas produtivas e sem elevada quantidade de lojas sem sementes, tal como já vem sendo feito desde 1950.

\section{1 - INTRODUÇÃO}

Um dos característicos a ser considerado no melhoramento do cafeeiro é o rendimento, isto é, a relação entre o pêso de café maduro ou sêco para o de café beneficiado. A ocorrência de maior quantidade de pericarpo, de

(*) Trabaiho apresentado ao II. Congresso Panaamericano de Agronomia, realizado em Piracicaba e São Pedro de 29 de março a 6 de abril de 1954.

Os autores agradecem aos Engs. Agrs. Adolfo Chebabi, José Luiz Vasconcellos da Rocha e Eudes Benassi pela colaboração prestada durante a coleta das amostras, e no sr. Luiz Bianchi, por facilitar a execução da amostragem realizada.

Recebido para publicação em 17 de setembro de 1954. 
sementes do tipo moca, de lojas do fruto desprovidas de sementes, bem como a baixa densidade das sementes, são alguns dos fatôres que podem influir desfavoràvelmente no rendimento do cafeeiro. $O$ estudo dêstes fatôres vem merecendo atenção especial no plano de melhoramento em execução na Seção de Genética do Instituto Agronômico, onde se tem procurado selecionar plantas de alta produção de frutos maduros e de bom rendimento.

Dentre os cafeeiros em observação destacam-se as progênies de um conjunto de plantas matrizes selecionadas no município de Urupês, S. P., as quais pertencem à variedade comercial atualmente chamada café Mundo Novo (3). Em geral êstes cafeciros mostram bom aspecto vegetativo e alta produção. Muitas plantas, porém, apesar de darem boas colheitas, apresentam alta incidência de frutos com lojas desprovidas de sementes e rendimento pouco satisfatório, enquanto outras, bern produtivas, não mostram êstes defeitos. $\hat{\mathrm{E}}$ possível que algumas plantas dêm quantidades elevadas de café beneficiado, a despeito do rendimento desfavorável, em virtude de produzirem grande quantidade de frutos. E preferível, no entanto, eliminar o defeito do café Mundo Novo de produzir lojas vazias, para que êste café possa ser distribuído scm restrições aos lavradores.

No presente trabalho estuda-se a produção das progênies e de algumas plantas individuais de café Mundo Novo de Campinas, expressa em quilogramas de frutos maduros e também em café beneficiado, e apresentam-se os resultados dos estudos realizados antes de ser efetuada a primeira distribuição de sementes deste café aos lavradores do Estado.

\section{2 - MATERIAL E METODO}

As presentes observações se limitam às progênies mais antigas de café Mundo Novo de Campinas, plantadas em 1944, e que constituem a população original, onde novas seleções vêm sendo feitas nestes últimos anos. Trata-se de um conjunto de 15 progênies com um total de 298 plantas, cujas produções vêm sendo controladas individualmente desde 1946 (3).

Em 1950 iniciou-se a determinação da incidência de lojas vazias, em amostras de 100 frutos maduros cortados transversalmente (1). Estas observações foram repetidas em 1951, 1952 e 1953, havendo, para cada planta, de 5 a 7 determinações, o que pcrmite estudar a variabilidade do número de lojas vazias, em anos diversos, para cada planta.

Nos anos de 1950 a 1952 guardaram-se amostras de frutos maduros de muitas plantas das diferentes progênies, a fim de se calcular seu rendimento. Dêste modo pôde-se calcular o rendimento médio para as plantas de cada progênie que apresentam alta e baixa incidência de lojas desprovidas de sementes e, subseqüentemente, calcular a sua produção expressa em café beneficiado.

\section{3 - RENDIMENTO}

A produção total média no período $1946-1953$ para as progênies de Campinas e a produção média das plantas com bajxa e com alta incidência 
de lojas sem sementes, expressa em frutos maduros e em café beneficiado, acham-se no quadro 1. Por ai pode-se observar que em seis de doze progênies examinadas quanto ao rendimento, o conjunto de plantas com alta incidência de lojas vazias ainda produz mais café beneficiado que o conjunto sem êste defeito. A classificação das plantas quanto à ocorrência de lojas vazias já foi efetuada em trabalho anterior $(1,3)$. É preciso ter em conta, porém, que os rendimentos não puderam ser calculados individualmente para tôdas as plantas, e que os valores usados na transformação de café cereja para beneficiado poderão variar quando se obtiverem dados mais precisos.

Quadro 1.-Produção total média (1946-1953) das progênies Mundo Novo de Campinas expressa em $\mathrm{kg}$ de frutos maduros e em $\mathrm{kg}$ de café beneficiado, baseada no rendimento calculado a partir de amostras para algumas plantas de cada progênie

\begin{tabular}{|c|c|c|c|c|c|c|c|c|c|c|c|}
\hline \multirow{4}{*}{ 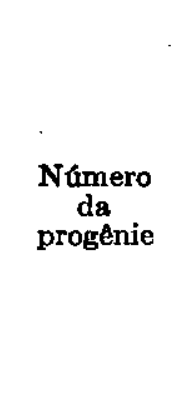 } & \multicolumn{11}{|c|}{ Produça total média por planta } \\
\hline & \multicolumn{5}{|c|}{ Café maduro } & \multicolumn{6}{|c|}{ Café beneficiado } \\
\hline & \multirow{2}{*}{$\begin{array}{l}\text { Proge- } \\
\text { nie } \\
\text { inteira }\end{array}$} & \multicolumn{2}{|c|}{$\begin{array}{c}\text { Plantas com } \\
\text { alta quantidade } \\
\text { de lojas vazias }\end{array}$} & \multicolumn{2}{|c|}{$\begin{array}{c}\text { Plantas com } \\
\text { baixa quanti- } \\
\text { dade de lojas } \\
\text { vazias } \\
\end{array}$} & \multicolumn{2}{|c|}{$\begin{array}{c}\text { Progenie } \\
\text { inteira }\end{array}$} & \multicolumn{2}{|c|}{$\begin{array}{c}\text { Plantas com } \\
\text { alta quantidade } \\
\text { de lojas vazias }\end{array}$} & \multicolumn{2}{|c|}{$\begin{array}{c}\text { Plantas com } \\
\text { baira quanti- } \\
\text { dade de lojas } \\
\text { vazias } \\
\end{array}$} \\
\hline & & $\begin{array}{c}\text { Produ-- } \\
\text { çẵo }\end{array}$ & $\begin{array}{l}\text { N.० de } \\
\text { plantas }\end{array}$ & $\begin{array}{c}\text { Produ- } \\
\text { sã̃o }\end{array}$ & $\begin{array}{l}\text { N. de de } \\
\text { plantas }\end{array}$ & $\begin{array}{l}\text { Rendi- } \\
\text { mento }\end{array}$ & $\begin{array}{c}\text { Produ- } \\
\text { são }\end{array}$ & $\begin{array}{l}\text { Rendi- } \\
\text { mento }\end{array}$ & $\underset{\text { Produ- }}{\text { çăo }}$ & $\begin{array}{l}\text { Rendi- } \\
\text { mento }\end{array}$ & $\begin{array}{l}\text { Produ- } \\
\text { ุāo }\end{array}$ \\
\hline & $\mathrm{kg}$ & $\mathrm{kg}$ & & $k g$ & & & $k g$ & & $k g$ & & $k g$ \\
\hline $\begin{array}{l}\text { CP } 374 \ldots \\
\text { CP } 375 \ldots \\
\text { CP } 376 \ldots \\
\text { CP } 379 \\
\text { CP } 381 \ldots\end{array}$ & $\begin{array}{l}29,9 \\
25,7 \\
35,4 \\
31,0 \\
30,0\end{array}$ & $\begin{array}{r}32,2 \\
27,8 \\
38,0 \\
-31,0\end{array}$ & $\begin{array}{r}9 \\
10 \\
13 \\
0 \\
15\end{array}$ & $\begin{array}{l}28,0 \\
23,6 \\
30,4 \\
31,0 \\
27,0\end{array}$ & $\begin{array}{r}11 \\
10 \\
7 \\
20 \\
5\end{array}$ & $\begin{array}{l}\mathbf{5 , 5 4} \\
5,83 \\
5,76 \\
5,21 \\
5,84\end{array}$ & $\begin{array}{l}\mathbf{5 , 4 0} \\
\mathbf{4 , 4 1} \\
\mathbf{6 , 1 5} \\
\mathbf{5 , 9 5} \\
\mathbf{5 , 1 4}\end{array}$ & $\begin{array}{r}6,11 \\
6,16 \\
6,22 \\
-6, \overline{8}\end{array}$ & $\begin{array}{r}5,27 \\
4,51 \\
6,11 \\
-4,86\end{array}$ & $\begin{array}{l}4,97 \\
5,50 \\
5,30 \\
5,21 \\
5,29\end{array}$ & $\begin{array}{l}5,68 \\
4,29 \\
5,74 \\
5,95 \\
5,10\end{array}$ \\
\hline $\begin{array}{l}\text { CP } 382 \ldots \\
\text { CP } 383 \ldots \\
\text { CP } 384 \\
\text { CP } 385 \\
\text { CP } 386 .\end{array}$ & $\begin{array}{l}29,2 \\
28,6 \\
27,1 \\
27,0 \\
28,4\end{array}$ & $\begin{array}{l}33,9 \\
31,4 \\
32,0 \\
25,6 \\
31,4\end{array}$ & $\begin{array}{r}4 \\
14 \\
3 \\
14 \\
13\end{array}$ & $\begin{array}{l}28,0 \\
21,9 \\
26,2 \\
30,3 \\
22,8\end{array}$ & $\begin{array}{r}16 \\
6 \\
17 \\
6 \\
7\end{array}$ & $\begin{array}{l}5,96 \\
5,82 \\
5,77\end{array}$ & $\begin{array}{l}4,80 \\
4,64 \\
4,92\end{array}$ & $\begin{array}{l}6,65 \\
6,48 \\
6,18\end{array}$ & $\begin{array}{l}4,72 \\
3,95 \\
5,08\end{array}$ & $\begin{array}{l}5,27 \\
5,15 \\
5,35\end{array}$ & $\begin{array}{l}4,10 \\
5,88 \\
4,26\end{array}$ \\
\hline $\begin{array}{l}\text { CP } 387 \ldots \\
\text { CP } 388 \ldots \\
\text { CP } 389 \ldots \\
\text { CP } 390 \ldots \\
\text { CP } 391 \ldots\end{array}$ & $\begin{array}{l}31,7 \\
29,5 \\
28,6 \\
23,6 \\
29,8\end{array}$ & $\begin{array}{l}34,4 \\
39,0 \\
31,2 \\
24,3 \\
29,5\end{array}$ & $\begin{array}{r}11 \\
2 \\
12 \\
16 \\
14\end{array}$ & $\begin{array}{l}30,2 \\
30,1 \\
24,6 \\
21,0 \\
30,3\end{array}$ & $\begin{array}{r}8 \\
17 \\
8 \\
4 \\
6\end{array}$ & $\begin{array}{l}\mathbf{5 , 7 9} \\
\mathbf{5 , 4 1} \\
\mathbf{5 , 4 0} \\
\mathbf{5 , 6 6} \\
\mathbf{5 , 5 5}\end{array}$ & $\begin{array}{l}\mathbf{5 , 4 7} \\
\mathbf{5 , 4 5} \\
\mathbf{5 , 3 0} \\
\mathbf{4 , 1 7} \\
\mathbf{5 , 3 7}\end{array}$ & $\begin{array}{l}\mathbf{6 , 2 9} \\
\mathbf{5 , 6 6} \\
\mathbf{5 , 9 2} \\
\mathbf{6 , 2 7} \\
\mathbf{6 , 2 3}\end{array}$ & $\begin{array}{l}5,47 \\
6,89 \\
5,27 \\
3,88 \\
4,74\end{array}$ & $\begin{array}{l}5,28 \\
5,15 \\
4,88 \\
5,04 \\
4,86\end{array}$ & $\begin{array}{l}\mathbf{5 , 7 2} \\
\mathbf{5 , 8 4} \\
\mathbf{5 , 0 4} \\
4,17 \\
\mathbf{6 , 2 3}\end{array}$ \\
\hline Média. & 29,0 & 31,6 & $\ldots$ & 27,0 & $\ldots$ & 5,66 & 5,17 & 6,21 & 5,06 & 5,16 & 5,23 \\
\hline
\end{tabular}

Segundo o quadro 1 também se nota que a classificação de progênies; baseada na produção média de frutos maduros, se altera pouco quando se determina a produção em café beneficiado, baseando-se no rendimento geral médio de tôdas as plantas das progênies $(r=0,93, \mathrm{~g} .1 .=11)$. Isto significa que a produção geral média de frutos maduros das progênies pode ser tomada como índice para a seleção das melhores progênies.

Considerando as médias dos rendimentos apresentados no quadro 1 para os cafeeiros com alta e com baixa quantidade de lojas vazias, é possível avaliar a relação que devem guardar entre sí as produções de frutos 
maduros dos dois tipos de plantas para que ambos dêm quantidades iguais de café beneficiado. Sendo os rendimentos respectivamente iguais a 6,21 e 5,16, verifica-se que as plantas com alta incidência do defeito precisariam ter produções de frutos maduros no mínimo $20,5 \%$ mais elevadas que as dos cafeeiros normais.

Quando se analisam as produções de café beneficiado de algumas das melhores plantas para as quais se tem calculado o rendimento individual, como se vê no quadro 2, pode-se notar a importância que apresenta a seleção de plantas com baixa incidência de frutos com lojas sem sementes, pois

QUADro 2.-Relação das produçóes totais (1946-1953) de algumas das melhores plantas Mundo Novo de Campinas, expressa em kg de café cereja e café beneficiado, obtida a partir do rendimento

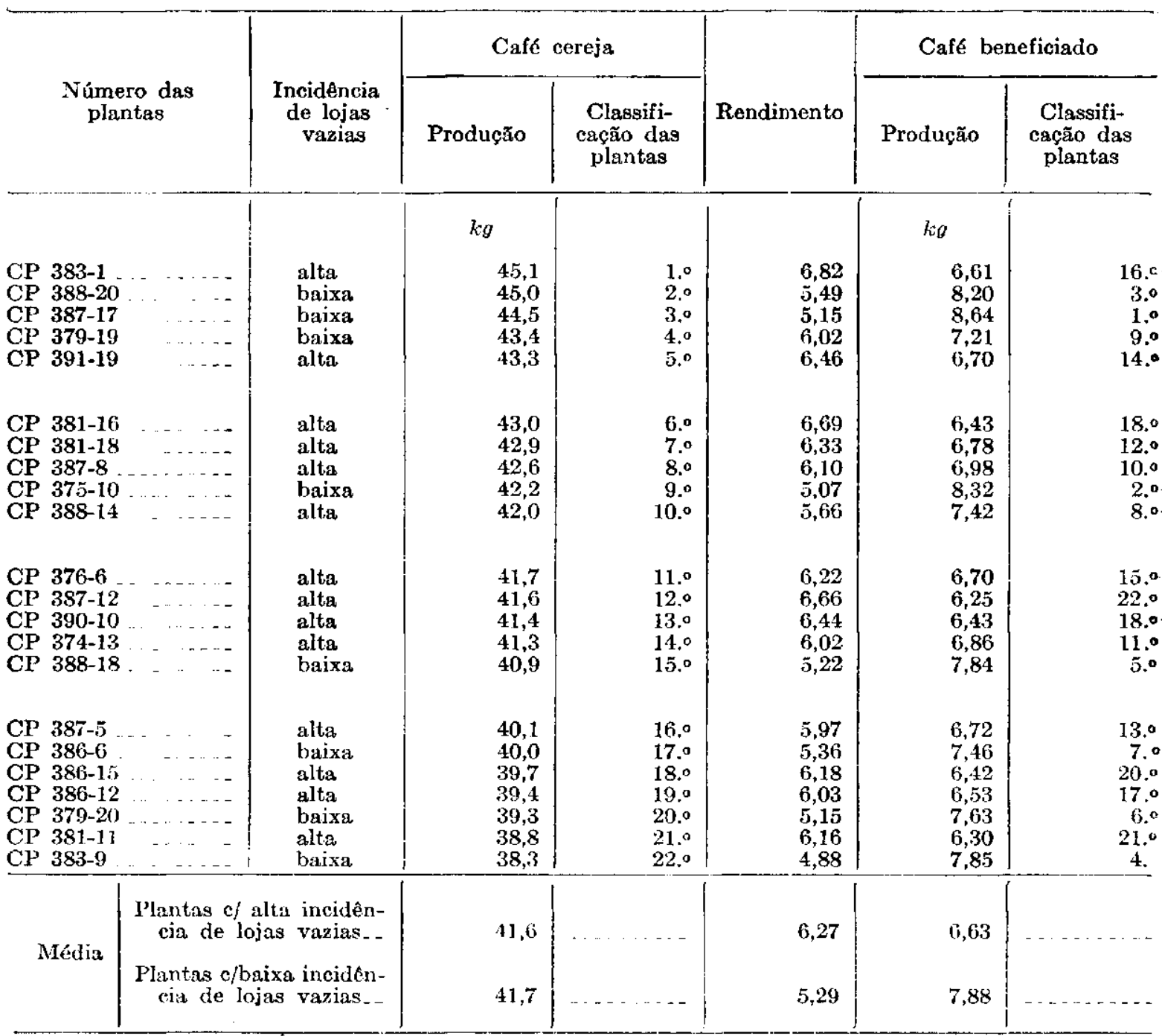

cafeeiros com menor produção de cerejas, porém de bom rendimento, como o CP 379-20, dão mais café beneficiado que outio cafeeiro produtor de maior quantidade de cereja, como o cafeeiro CP 383-1, de rendimento inferior (quadro 2). Considerando os dois grupos de plantas (14 com alta e oito com baixa incidência de lojas vazias), mencionados no quadro 2 , veri- 
fica-se que suas produçбes de cerejas são iguais, enquanto seus rendimentos diferem significativamente $(\mathrm{P}=0,01)$, o que indica que as produções de café beneficiado são maiores para o grupo de plantas de baixa incidência de lojas vazias. Pela relação dos rendimentos médios, 6,27 e 5,29 para êsses dois grupos de plantas, verifica-se, novamente, que a produção de cerejas das plantas com alta incidência do defeito precisa ser $18,5 \%$ maior que a das plantas normais, para que dêm a mesma quantidade de café beneficiado.

Em 1953 procurou-se determinar até que ponto o defeito "lojas vazias" influe sôbre o rendimento. Para êsse fim, os frutos maduros colhidos em vários cafeeiros Mundo Novo que apresentam elevada incidência de lojas vazias foram colocados em um recipiente com água. Sendo mais leves, flutuam as cerejas que contêm lojas vazias, separando-se fàcilmente das demais, que não apresentam êsse defeito. Da parte que flutuou, retiraram-se seis amostras de $5 \mathrm{~kg}$ cada uma. Outras seis amostras, também de $5 \mathrm{~kg}$, foram retiradas da parte que submergiu no recipiente. Nas 12 amostras efetuáram-se determinações do volume de frutos maduros, do pêso e do volume de café sêco. Depois de beneficiadas, tomaram-se o pêso e o volume de café beneficiado obtido em cada uma. No quadro 3 encontram-se as médias das determinações feitas.

Quadro 3.-Pêso, volume e rendimento de vários tipos de frutos de café beneficiado do café Mundo Novo (médias de seis determinações)

\begin{tabular}{|c|c|c|c|c|c|c|c|c|}
\hline \multirow{3}{*}{$\begin{array}{l}\text { Classificagá dos } \\
\text { frutos maduros }\end{array}$} & \multicolumn{6}{|c|}{ Tipo de café } & \multicolumn{2}{|c|}{ Rendimento } \\
\hline & \multicolumn{2}{|c|}{ Fruto maduro } & \multicolumn{2}{|c|}{$\begin{array}{c}\text { Fruto sêco com } \\
\text { casca }\end{array}$} & \multicolumn{2}{|c|}{ Beneficiado } & \multirow{2}{*}{ Mad./benef. } & \multirow{2}{*}{ Seco/benef. } \\
\hline & pêso & volume & peso & volume & pêso & volume & & \\
\hline $\begin{array}{l}\text { Parte que flutuou } \\
\text { na agua }\end{array}$ & $\begin{array}{l}g \\
5000\end{array}$ & $\begin{array}{c}l \\
9,300\end{array}$ & 1560 & $\begin{array}{c}l \\
4,390\end{array}$ & 455 & $\begin{array}{c}l \\
0,670\end{array}$ & 10,99 & 3,43 \\
\hline $\begin{array}{l}\text { Parte que submer- } \\
\text { giu na f́gua -- }\end{array}$ & 5000 & 8,000 & 1740 & 3,830 & 778 & 1,170 & 6,43 & 2,24 \\
\hline
\end{tabular}

Nota-se que, apesar de ser um pouco desfavorável, a relação média entre os pesos de café maduro e de café beneficiado verificada para as seis amostras retiradas do fundo do recipiente $(6,43)$, difere sensivelmente do valor 10,99, que representa a média da mesma relação obtida para as seis amostras de frutos que sobrenadaram. Comparando-se os valores calculados para as relações entre pêso de café em côco (sêco) e pêso de café beneficiado, para ambas as séries de amostras, verifica-se que as diferenças são aproximadamente da mesma grandeza.

É desnecessário frizar que os valores 10,99 e 3,43 são extremos obtidos pelo processo acima descrito. Não obstante, servem êles para demonstrar o prejuízo máximo que pode advir de um excesso de frutos com lojas vazias. $O$ valor 3,43 , da relação entre pêsos de café em côco e café beneficiado, para as amostras de frutos que flutuaram, significa que um saco de $40 \mathrm{~kg}$ de café em côco renderia, no benefício, apenas 11,7 kg de café beneficiado. 
Admitindo uma relação linear entre a proporção de frutos com lojas vazias e os rendimentos, com os dados do quadro 3 , vê-se que o rendimento $\mathbf{R}$, para amostras com uma parte $\mathbf{x}$ de frutos que flutuam e $\mathbf{1 - x}$ que não flutuam será igual a $6,43+4,57 \mathbf{x}$. Para amostras nas quais flutuam $35 \%$ dos frutos, ter-se-ia $\mathbf{R}=6,43+4,57 \times 0,35=8,03$. De modo mais geral esta equação pode ser assim expressa: $\mathbf{R}=\mathbf{R}_{1}+\left(\mathbf{R}_{2}\right.$ - $\mathbf{R}_{1}$ ) $\mathbf{x}$, onde $\mathbf{R}_{1}$ e $\mathbf{R}_{2}$ são os rendimentos calculados para os frutos que não flutuam e para os que flutuam, respectivamente. Outras determinações precisam ser efetuadas, a fim de melhor elucidar esta questão.

A fim de verificar se a quantidade de lojas vazias seria influenciada pela enxertia, a Secção de Café do Instituto Agronômico fez enxertos, sôbre a var. maragogipe (C. arabica L. var. maragogipe Hort. ex Froehner), das plantas CP 381-4, CP 381-11 e CP 381-12, cujas médias de lojas vazias por 100 frutos produzidos são 35,32 e 28 respectivamente. As médias para os enxertos dessas plantas foram 44,35 e 33 respectivamente, semelhantes pois à dos cafeeiros de pé franco, indicando que a enxertia pouco influência a ocorrência dêsse fenômeno e conseqiientemente o rendimento.

\section{4 - PRIMEIRAS DISTRIBUIÇÕES DE SEMENTES DE CAFÉ MUNDO NOVO AOS LAVRADORES}

As primeiras observações feitas sôbre as progênies de Mundo Novo indicaram tratar-se de café bastante rústico e produtivo, motivo pelo qual, em 1950, pensou-se em iniciar distribuição de sementes a um pequeno grupo de lavradores, a fim de estudar o comportamento dêste café em maior escala.

As observações realizadas naquele ano sôbre \& ocorrência de lojas vazias nos frutos indicaram a existência de progênies onde tôdas as plantas eram normais, e de progênies com alguns cafeeiros normais ao lado de outros com alta incidência do defeito (3). Observações análogas efetuadas em outros cafeeiros da variedade bourbon (Coffea arabica L. var. bourbon (B. Rodr.) Choussy) mostraram que o de n. ${ }^{\circ} 44$ da Seção de Genética também apresentava alta incidência de lojas sem sementes. Progênies dêsse cafeeiro correspondentes às gerações $F_{1}$ e $F_{2}$ e alguns híbridos $F_{1}$ com plantas normais, foram, em 1950, aproveitados para se fazer determinações do número de lojas vazias. Os resultados indicaram que na progênie $\mathrm{F}_{1}$ da planta n. ${ }^{\circ} 44$ e nos seus híbridos $\mathrm{F}_{1}$ existiam plantas com e sem o defeito, e que os indivíduos normais da progênie $F_{1}$ davam, por sua vez, na geração $F_{2}$, progênies constituídas apenas por plantas normais, sugerindo ser relativamente fácil a seleção visando eliminar a alta incidência de lojas vazias.

Levando em conta êstes resultados resolveu-se, em 1950, iniciar a distribuição de sementes do café Mundo Novo colhidas apenas em plantas de alta produção e onde a incidência de lojas vazias era mínima, pois seria de se esperar que o mesmo mecanismo genético encontrado no cafeeiro 44 controlasse também a ocorrência do defeito no café Mundo Novo. Uma das primeiras propriedades que receberam sementes do Mundo Novo, selecionadas segundo êste critério, foi a Granja Paraíso, localizada em Itatiba, S. P., de 
propriedade do sr. Luíz E. Bianchi. As sementes das seguintes linhagens foram entregues, em 6 de setembro de 1950, ao Eng. Agr. Adolfo Chebabi, que se achava encarregado do plantio de café naquela propriedade:

\begin{tabular}{|c|c|c|c|}
\hline N. ${ }^{\circ}$ A Linhage & & $\begin{array}{l}\text { Quantidade de } \\
\text { sementes em } \mathrm{kg}\end{array}$ & $\begin{array}{c}\text { Nümero aproximado } \\
\text { de pés de cafe( }\left(^{*}\right)\end{array}$ \\
\hline LCP 374 & ......... & 1,9 & 2.000 \\
\hline LCP 376 & 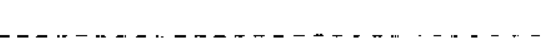 & 1,9 & 2.200 \\
\hline LCP 379 . & 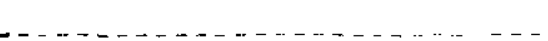 & 1,0 & 400 \\
\hline LCP 381 & - & 1,0 & 100 \\
\hline LCP 386 & - & 2,0 & --- \\
\hline LCP 387 - & $\ldots \ldots$ & 2,0 & 2.200 \\
\hline & $\ldots \ldots \ldots$ & 9,8 & 6.900 \\
\hline
\end{tabular}

Com essas sementes foram plantadas, em nível, 6.900 covas de café a quatro plantas por cova. A linhagem LCP 386 não foi plantada na Granja Paraíso.

A produção assinalada em 1952 foi muito reduzida, sendo bem razoável a que se verificou em 1953. Devido ao grande interêsse dos lavradores pelo café Mundo Novo e não dispondo de sementes em quantidade suficiente para atendê-los, o Eng. Agr. Helio de Morais, da Seção de Café da Divisão de Fomento Agrícola, consultou as Seções de Café e de Genética do Instituto Agronômico sóbre a possibilidade de adquirir tôdas as sementes de Mundo Novo produzidas em 1953 pela Granja Paraíso, para formar cêrca de 150 "plantações-modêlo" no Estado de São Paulo e que iriam, nos próximos anos, servir de campo de aumento dessas linhagens.

Consultou-se a Seção de Técnica Experimental e Cálculo dêste Instituto, a fim de se avaliar estatìsticamente a freqüência de plantas com alta incidência de lojas vazias, nas linhagens plantadas na Granja Paraíso. Foi decidido que o número de amostras deveria ser proporcional ao número de plantas existentes nas diversas linhagens, sorteando-se a cova da qual seria retirada a primeira amostra. De um dos quatro cafeeiros existentes em cada cova, colheram-se 100 frutos maduros que a seguir foram postos em água, contando-se quantos flutuavam. Os dados obtidos dêsse estudo acham-se no quadro 4.

QUadro 4.-Cafeeiros existentes na Granja Paraíso, classificação das amostras coletadas e limites prováveis $(P=0,05)$ de porcentagem de plantas com o defeito de alta incidência de lojas vazias

\begin{tabular}{|c|c|c|c|c|c|}
\hline \multirow[b]{2}{*}{ N.० da linhagem } & \multicolumn{4}{|c|}{ Número de plantas } & \multirow[b]{2}{*}{$\begin{array}{c}\text { Plantas com } \\
\text { defeito } \\
(P=0,05)\end{array}$} \\
\hline & existentes & amostradas & $\begin{array}{l}\text { com alta in- } \\
\text { cidencia de } \\
\text { lojas vazias }\end{array}$ & $\begin{array}{l}\text { com baixa } \\
\text { incidência de } \\
\text { lojas vazias }\end{array}$ & \\
\hline $\begin{array}{l}\text { LCP } 374 \\
\text { LCP } \mathbf{3 7 6} \\
\text { LCP } \mathbf{3 7 9} \\
\text { LCP } 381\end{array}$ & $\begin{array}{r}n .{ }^{\circ} \\
2000 \\
2200 \\
400 \\
100\end{array}$ & $\begin{array}{rr}n .0 & \\
& 72 \\
& 67 \\
& 9\end{array}$ & $\begin{array}{l}8 \\
2 \\
0\end{array}$ & $\begin{array}{r}64 \\
65 \\
9\end{array}$ & $\begin{array}{r}6 \% \\
\begin{array}{r}6 \\
0\end{array} \text { a } 22 \\
\end{array}$ \\
\hline LCP 387 Total & $\begin{array}{l}2200 \\
6900\end{array}$ & 1275 & $\begin{array}{r}0 \\
10\end{array}$ & 265 & $\begin{array}{lll}0 & \text { a } & 3 \\
2 & a & 7\end{array}$ \\
\hline
\end{tabular}

(*) Dados gentilmente fornecidos pelo Eng. Agr. A. Chebabi. 
A maior incidência de plantas com alta quantidade de lojas vazias encontrada na linhagem LCP 374, deve-se provàvelmente ao fato das sementes provirem, em parte, do cafeeiro CP 374-19. A julgar pela primeira determinação feita em 1950, acreditava-se que êste cafeeiro tivesse baixa incidência de lojas vazias; na realidade, porém, apresenta elevada incidência desse defeito, como demonstraram determineucões posteriores.

A porcentagem de plantas com alta incidência de lojas sem sementes na linhagem LCP 374 deve ter um valor compreendido entre 6 e 22 ( $\mathrm{P}=$ $=0,05$ ), de acôrdo com os dados obtidos da arnostragem; na linhagem LCP 376 a porcentagem será no máximo de 11, e de 3 na linhagem LCP 387. A progênie CP 379 é constituída apenas de plantas normais, de modo que era de se esperar que não fôsse encontrada planta alguma com êsse defeito na linhagem correspondente; de fato, a amostragem não revelou a ocorrência de plantas com defeito.

As progênies originais de Campinas, CP 374:, CP 376, CP 379 e CP 387 são formadas dos seguintes números de plantas com alta e baixa incidência de lojas vazias :

Progênies

Plantas com incidencia de lojas vazias

CP 374 alta baixa

CP 376 9

CP 379

CP 387

Considerando as progênies que contêm os dois tipos de plantas, há 26 cafeeiros com baixa, e 33 com alta incidência de lojas vazias, o que corresponde a mais de $50 \%$ de plantas com o defeito.

Porcentagem semelhante de plantas com alta incidência de lojas vazias foi verificada em 1952, na Fazenda Ferrari, do sr. Ângelo Zancaner, em Catanduva, S. P.. Ao se determinar a frequiência de lojas vazias em 30 cafeeiros que se destacavam pelo aspecto vegetativo e alta produção de cerejas, verificou-se que 16 deles apresentavam alta incidência dessa anomalia, o que também corresponde a cêrca de $50 \%$ de plantas indesejáveis. Em trabalho anterior já se demonstrou que esta $\epsilon$ aproximadamente a proporção de plantas com alta incidência de lojas vazias que deve ser encontrada em plantações Mundo Novo formadas com sementes tiradas ao acaso, sem seleção visando eliminar o defeito (1).

Considerando o total de 275 indivíduos examinados nas várias linhagens da Granja Paraíso, vê-se que apenas 10 mostraram alta incidência do defeito em questão, o que corresponde a um míximo de $7 \%$ de plantas dessa natureza $(P=0,05)$. Em um conjunto de 68 plantas da variedade bourbon, em seleção em Campinas, também se encontrou a ocorrência de dois indivíduos com êsse defeito, correspondendo à porcentagem máxima de $11(\mathrm{P}=0,05)$. Isso indica que na população atual de cafeeiros Mundo Novo da Granja Paraíso a freqüência de cafeeiros com alta incidência de lojas vazias é igual à verificada em cafeeiros bourbon, e que essa freqüência já difere bastante da que se verificou nas populaçôes originais mencionadas. 
Em vista dos resultados obtidos, a Divisão de Fomento Agrícola distribuiu, entre numerosas propriedades particulares, cêrca de duas toneladas de sementes de Mundo Novo oriundas da Granja Paraíso, com o objetivo de formar 148 pequenas "plantações-modêlo", de 5.000 a 10.000 pés cada uma, usando as normas de plantio e formação de cafèzal preconizadas pclo Instituto Agronômico. E provável que a maior parte destas novas plantações seja temporàriamente aproveitada para produção de sementes. Espera-se, assim, que em breve os lavradores possam contar com elevada quantidade de sementes de Mundo Novo para formar novas lavouras e replantar seus cafèzais.

\section{5 - DISCUSSÃO}

A amostragem efetuada na plantação de café Mundo Novo da Granja Paraíso veio confirmar as previsões feitas em 1950, de que a proporção de cafeeiros com elevada incidência de lojas vazias estaria alí reduzida a um mínimo. Realmente, os dados indicam que a proporção de plantas dêste tipo não vai além de $7 \%$, a qual é particularmente significativa quando se considera que, no café Mundo Novo não selecionado em relação a êsse característico, a proporção de plantas com excesso de lojas vazias é de cêrca de $50 \%$ (1).

Resta explicar porque não foi total a eliminação de plantas assim defeituosas no restante da plantação, excluindo-se a linhagem LCP 374 . Em primeiro lugar, há que ter em conta que as sementes utilizadas na formação do cafèzal da Granja Paraíso provinham de polinização livre, tendo sido colhidas em cafeeiros com baixa incidência de lojas vazias. Tôda evidência até agora acumulada indica que nas progênies obtidas por autofecundação de plantas que apresentam baixa quantidade de lojas vazias, encontram-se apenas cafeeiros normais. Admitindo-se porém que o café Mundo Novo se comporte como a variedade cera (C. arabica L. var. cera K.M.C.), cêrca de $10 \%$ de suas sementes serão produtos de polinização cruzada (2). Enquanto não for perfeitamente esclarecida a hereditariedade do característico excesso de lojas vazias, deve ser considerada a hipótese de que o encontro de plantas com tal defeito, em progênies formadas com sementes de polinização livre, seja atribuível a cruzamentos naturais, ainda que as plantas envolvidas nos cruzamentos sejam normais com respeito ao defeito em aprêço.

Quanto aos novos cafèzais que se formarem com as sementes produzidas pela Granja Paraíso, ou por qualquer outra propriedade agrícola que se enquadre nas mesmas circunstâncias, pode-se esperar que também apresentem pequena proporção de plantas com alta incidência de lojas vazias. Esta afirmação baseia-se nos resultados da amostragem, apresentados neste trabalho. Havendo 2 a $7 \%$ de plantas indesejáveis nessa população, as gerações scguintes apresentariam as mesmas proporções de tal classe de cafeeiros, desde que não houvesse seleção natural ou artificial em favor de uma das duas categorias de plantas.

Um simples cáleulo mostra a importância de selecionar indivíduos normais, livres do defeito de lojas vazias, no café Mundo Novo. Para que uma 
planta ou grupo de plantas com alta incidência de lojas vazias produza a mesma quantidade de café beneficiado que outra planta ou outro grupo sem aquele defeito, será preciso que suas produções de frutos maduros e seus rendimentos guardem entre sí a seguinte relação:

$$
\frac{\mathbf{C}_{\mathrm{a}}}{\mathbf{R}_{\mathrm{a}}}=\frac{\mathbf{C}_{\mathrm{b}}}{\mathbf{R}_{\mathrm{b}}}
$$

onde $\mathbf{C}_{a}$ e $\mathbf{C}_{b}$ são as produções, $\mathrm{cm}$ quilogramas de frutos maduros, das plantas com alta e com baixa incidência de lojas vazias, respectivamente; $\mathbf{R}_{a}$ e $\mathbf{R}_{b}$, representam os valores calculados do rendimento (relação entre pêsos de café maduro e café beneficiado) para as mesmas duas classes de cafeeiros. Desta relação tira-se

$$
\mathbf{C}_{\mathbf{a}}=\mathbf{C}_{\mathrm{b}} \frac{\mathbf{R}_{\mathrm{a}}}{\mathbf{R}_{\mathrm{b}}}
$$

Devido à presença de lojas vazias, é provável que os valores calculados: para $\mathbf{R}_{\mathbf{a}}$ sejam sempre mais elevados que os de $\boldsymbol{F}_{\mathrm{b}}$ (quadro 2). Segue-sc, pois, que a fração $\mathbf{R}_{\mathrm{a}} / \mathbf{R}_{\mathrm{b}}$ constitui um fator que exprime quantas vêzes a produção de café maduro das plantas com muitas lojas vazias deverá scr maior do que a produção das plantas normais, para que as duas categorias de plantas dêm a mesma quantidade de café beneficiado. Verifica-se no quadro 2 que a produção média em quilogramas de café cereja, no período 1946/1953, para os oito cafeeiros com baixa incidéncia de lojas vazias, foi de $41,7 \mathrm{~kg}\left(\mathbf{C}_{\mathrm{b}}\right)$. Ainda no quadro 2 , vê-se que $\mathbf{R}_{\mathrm{a}}$ ə $\mathbf{R}_{\mathrm{b}}$ são respectivamente iguais a 6,27 e 5,29. Estes valores pcrmitem calcular a produção de café cereja $\left(\mathbf{C}_{\mathbf{a}}\right)$, das 14 plantas com excesso de lojas vazias, a fim de que elas dêm tanto café beneficiado quanto as oito plantas normais:

$$
\mathbf{C}_{a}=41,7 \frac{6,27}{5,29}=49,4 \mathrm{~kg}
$$

Vê-se que a produção média das 14 plantas com excesso de lojas vazias precisaria ser de $49,4 \mathrm{~kg}$, isto é, $18,5 \%$ superior à produção média das oito plantas normais, a fim de que elas pudessem dar café beneficiado em quantidade pelo menos igual à que pode ser produzida pelos cafceiros normais. Na verdade, a produção de frutos maduros dessas 14 plantas foi igual à dos oito indivíduos normais, ao passo que a produção de eafé beneficiado foi sensivelmente inferior. A relação dos rendimentos médios apresentados no quadro 1 , dá um valor de $20,5 \%$, semelhante pois so encontrado pura as melhores plantas do quadro $2(18,5 \%)$.

Os dados disponíveis não são ainda suficientes para conclusões mais precisas, uma vez que a relação discutida depende de valores até agora determinados com número relativamente pequeno de amostras $\left(\mathbf{R}_{\mathfrak{a}}\right.$ e $\left.\mathbf{R}_{\mathrm{b}}\right)$, e que podem variar, dentro de certos limites, para o mesmo cafeeiro. Não obstante, pode-se concluir preliminarmente que dentre os indivíduos com alta incidência de lojas vazias mcreceriam ser selecionados ùnicamcnte aquêles que tivessem produços excepcionais de frutos maduros. Mesmo 
assim, esta scleção visaria tão sòmente aproveitá-los para derivar progênies em que poderiam aparecer alguns descendentes igualmente produtivos e livres do defeito, ou em cruzamento com outros indivíduos de elevada produtividade. Ao que parece, porém, não há grandes diferenças entre as produções de frutos maduros das melhores plantas com baixa ou com alta incidência de lojas vazias. Mesmo que mais tarde venha a ser encontrada alguma vantagem a favor da segunda categoria de cafeeiros, difìcilmente a diferença atingirá a magnitiude exigida pela disparidade dos rendimentos, para que seja compensadora a produção de café beneficiado.

Estas considerações justificam a decisão tomada pela Seção de Genética, de aproveitar primeiramente apenas os cafeciros Mundo Novo que sejam produtivos e que apresentem frutos com o mínimo de lojas vazias.

A eficiência que foi assinalada na eliminação dêste defeito, tornada evidente pela amostragem efetuada na Granja Paraíso, equivale, realmente, a um aumento da capacidade de produção de Café Mundo Novo.

\section{COFFEE BREEDING}

\section{$X$... SELECTION TO ELIMINATE PLANTS WITH HIGH FREQUENCY OF EMPTY FRUIT LOCULAS IN TILE MUNDO NOVO COFFEE}

\section{SCMMARY}

A high proportion of plants of the Mundo Novo coffee (a strain of Coffea arabica L. var. bourbon (B. Rodr.) Choussy) produce an abnormally large number of fruits with empty locules. Since this character reduces the rate of coffee beans per weight of fruit, selection was started aiming at reducing or eliminating plants having this dofect, and thereby increasing the yeild of coffec beans.

Preliminary investigations carried out in 1950 on the occurrence of empty locules in selied progenies and hybrids of the bourbon plant $\mathrm{No}_{0}$. 44, which presents a high percentage of this refect, indieated that this characteristic was heritable. It was also determined that only normal plants were found in progenies of normal individuals, even when these belonged to progenies in which some of the sibs produced large number of fruits with empty locules. Based on this information, sceds from normal, high yielding plants of Mundo Novo coffee were released to coffec growers in 1950 .

In one of the first farms to use selected seeds of Mundo Novo coffee, approximately 7,000 trees (one tree is really a group of four platnts in the same hill) were planted with seeds produced by the best plants of five of the most outstanding progenies of this variety. A small crop was available in 1953. 1)ue to the increasing demand for selected seeds of Mundo Novo coffee, it was then suggested that the State Extension Service buy the sceds produced in this farm and distribute them to coffee growers that were willing to plant them for seed production. Before this suggestion was put into eflect, the whole planting was surveyed for the presence of plants producing large numbers of fruits with empty locules. By means of a sampling technique, it : was determined that only from 2 to 7 per cent of abnormal plants were found in the plantalion. When these numbers were contrasted with the 50 per cent index of undesirable trees normally found in the original Nundo Novo plantings, it became evident that selection to eliminate plants producing large number of fruit with empty locules had been quite successful. If must, be noted that such a low pereentage of undesirable plants having the same defective character is normally found in plantings of the current commercial varieties such as bourbon and others.

Details of the sampling results and the influence of a high rate of empty locuels on the yield of coffee beans are discussed. The possibility of selecting exeeptionally high-yielding individuals, although having this defect, is consideret. 
The elimination of trees which gave unusually large quantity of fruit with empty locules allowed the establishment of pilot plantings. It m\&y be said that an increase in productivity was attained by this method of selection.

\section{LITERATURA CITADA}

1. ANTUNES, H. (filho) \& CARVAlHo, A. Melhoramento do cafeeiro. VII. Ocorrência de lojas vazias em frutos do café Mundo Novo. Bragantia 13:[165]179. 1954.

2. CARVAlho, A. \& KRUG, C. A. Agentes da polinização da flor do cafeeiro (Coffea arabica L.). Bragantia 9:[11]-24. 1949.

3. MENDES, J. E. T. [c outros]. Melhoramento do cafeciro. IV. Café Mundo Novo. Bragantia 12:[97]-129. 1952. 